\title{
Social Eclipses and Reversion to Type: Sexual Issues Confronting Postmodern Men and Women Working in Strongly Patriarchal Societies
}

\begin{abstract}
John Markert ${ }^{1}$
Globalization is changing the face of the world. But doing business in the international arena is not without its pitfalls. One area that has received attention is the potential for misunderstandings that can occur when two companies that are culturally different do business with one another. A problem which may exacerbate cultural conflict in the international arenas is when the policy of the corporate parent and the mores of its management team are at odds with the values of employees in the host country. The potential for a cultural clash is particularly pronounced when the challenges to patriarchy that are addressed in the sexual harassment policy in the United States and other postmodern societies collide with the tradition of patriarch in the host country. "Modern" men and women who suddenly find themselves immersed in a strongly patriarchal culture might be "forced" to adapt. This is likely because a social eclipse has occurred. This paper introduces the concept of a social eclipse as a variation to Erving Goffman's concept of a Total Institution. It goes on to explore why those with "advanced" ideas of gender equality might revert to type, and the social conditions that can cause a resurgence in patriarchal beliefs. [Article copies available for a fee from The Transformative Studies Institute. E-mail address: journal@transformativestudies.org Website:

http://www.transformativestudies.org (C)2009 by The Transformative Studies Institute. All rights reserved.]
\end{abstract}

KEYWORDS: Sexual Harassment, Globalization, Total Institutions, Social Eclipse, Patriarchy, Sexism.

\footnotetext{
${ }^{1}$ Dr. John Markert is associate professor of sociology at Cumberland University, a small liberal arts college outside of Nashville. He obtained his B. A. and M.A. in sociology from the University of South Florida and his Ph.D. in sociology from Vanderbilt University. Recent articles have appeared in, Critical Sociology, Sociological Imagination, Sociological Spectrum, Bilingual Review; The Social Science Journal, Advances in Gender Research, Volume 9, and the Journal of Current Issues and Research in Advertising. Address correspondence to: John Markert, 1913 18th Avenue South Nashville, TN 37212; tel: 615-292-7819; e-mail: john_markert@comcast.net. Acknowledgements: The author thanks the anonymous reviewers at Theory in Action for their insightful comments on an earlier draft of this paper, and the editors for their encouragement to revise and resubmit the paper.
} 